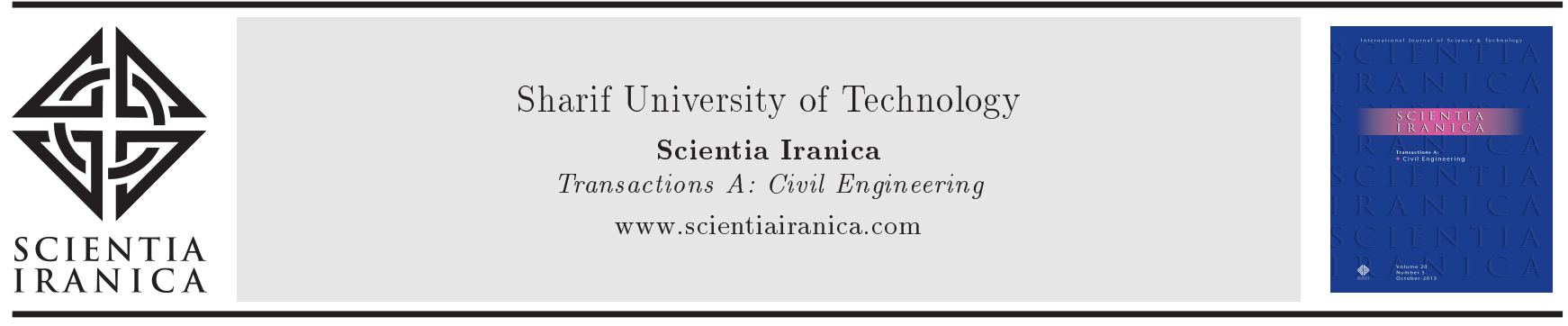

\title{
Simulating FRP debonding from concrete surface in FRP strengthened RC beams: A case study
}

\author{
D. Mostofinejad and S.J. Hosseini* \\ Department of Civil Engineering, Isfahan University of Technology (IUT), Isfahan, Iran.
}

Received 1 February 2015; received in revised form 17 October 2015; accepted 13 February 2016

\section{KEYWORDS}

Flexural

strengthening;

Debonding;

Fiber reinforcement

polymers;

Finite element

method.

\begin{abstract}
Reinforced Concrete (RC) beams strengthened with Fiber Reinforced Polymer (FRP) sheets may fail due to debonding failure. In such cases, the FRP sheet is detached from the RC beam before real damages are inflicted on the beam. In this paper, a procedure is developed based on smeared cracks approach for simulating the debonding process in FRP strengthened RC beams within the framework of finite element. For this purpose, the challenges facing the simulation of debonding mechanism are initially studied, and a method is proposed in a second stage of combating these problems using the cohesive elements available in the ABAQUS software. The validity of the proposed method is then tested by modeling four beams from those reported in the literature and by comparing the results with the experimental ones. Given the acceptable agreement observed between the experimental and numerical simulation results, the method is claimed to be valid and practicable. In a later section of the present paper, the proposed method will be used to investigate the effects of length and width of the strengthening sheet on beam's behavior and its failure mechanism. The results of the present study reveal that longer FRP sheets increase load carrying capacity and mid-span displacement of strengthened RC beams.
\end{abstract}

(C) 2017 Sharif University of Technology. All rights reserved.

\section{Introduction}

Regarding the fact that most existing structures have life spans of several decades, their strengthening has now become a major concern and the greatest challenge facing structural engineers. A number of methods are presently available for this purpose, the selection of which depends on a multitude of factors. The unique properties of Fiber Reinforced Polymers (FRPs) used as internal rods or externally bonded sheets/laminates have made them the most common method to strengthen RC beams [1]. Despite the advantages associated with using FRPs in strengthening

*. Corresponding author. Tel.: +98 31 32630332;

Fax: +98 31333912700

E-mail addresses: dmostofi@cc.iut.ac.ir (D. Mostofinejad); civil.hoseini@gmail.com (S.J.Hosseini)
$\mathrm{RC}$ beams, they have their own limitations as well, the greatest being their debonding failure. Debonding means separation or peeling off of the FRP sheet during loading when no element, the concrete or the FRP sheet, has yet experienced any serious damage and still retains its load-carrying capacity (Figure 1 ).

In general, debonding failure mechanisms may be classified into two categories: plate end debonding and mid-span debonding. These two types of debonding differ not only with respect to their debonding initiation location, but also in terms of their causes. The cause of the plate end debonding is the emergence of cracks due to abrupt failure of the FRP sheet. In other words, the cutoff of FRP sheets at one point creates high interfacial shear and normal stresses at its ends. This concentrated stress will then lead to the propagation of cracks in the epoxy and its adjacent concrete layer; the development of these cracks will 


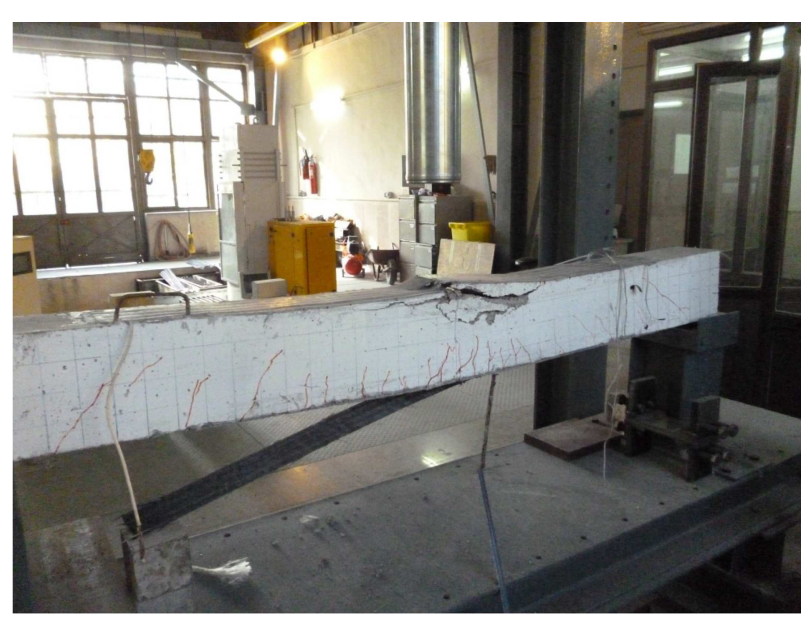

Figure 1. Debonding failure between beam and plate.

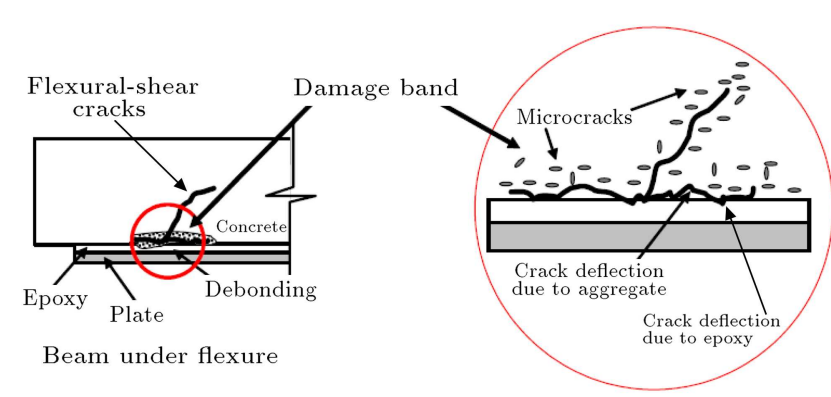

Figure 2. Mid-span cracking mechanism [17].

finally cause the peeling off of the FRP sheet from the concrete surface [1]. Mid-span debonding typically initiates with a flexural or flexural-shear cracking that propagates to the beam end. A significant displacement usually occurs at the crack location due to crack opening which gives rise to a highly local interfacial stress at the interface between the concrete and the epoxy.

Since the ultimate shear strength of the epoxy is several times the shear strength of concrete, the local shear stress leads to micro-cracks in the beam's substrate layer adjacent to epoxy-concrete interface (Figure 2). As the micro-cracks propagate and join the concrete-FRP sheet interface, cracks parallel to the beam axis will form, which will further grow with increasing load until they finally reach the beam end, where they cause the competition of debonding of the FRP sheet.

Based on these observations, the crack location must be a few millimeters above the interface. This is the reason why after each debonding, a concrete layer, $1 \mathrm{~mm}$ in thickness, is normally seen sticking to the debonded FRP sheet [2]. This layer (i.e., the epoxy and the adjacent concrete) is called the interfacial layer.

Previous studies have shown that debonding may be predicted by exploiting either the Linear Elastic Fracture Mechanics (LEFM) or the cohesive interface to induce the behavior of interfacial layer in numerical simulations. In the LEFM method, the appearance and evolution of cracks created at the interface are determined by evaluating one of the common fracture mechanical parameters, such as the energy release rate or the $J$ integral at the interface, and comparing the obtained values with the corresponding critical values determined from the mechanical characteristics of concrete, the adhesive material used, and the composite plate. Greco (2007) [3], Esna-Ashari and Mohammadi (2012) [4], and Bruno et al. (2013) [5] used this method. In the other method, cohesive interfaces are mathematical concepts or special elements defined between the strengthening plate and the concrete beam that induce slip and debonding in the numerical solution. In other words, these interfaces respond to tangential or normal traction according to a constitutive relationships and lead to the slip and debonding of the strengthening plate relative to the concrete. This method has been employed in a number of studies including Täljsten (1997) [6], Wu and Hemdan (2004) [7], Wang (2006) [8], Lu et al (2007) [9], De Lorenzis and Zavarise (2009) [10], and Rabinovitch (2014) [11].

In the present study, finite element method is used for numerical simulation. Crack growth effects may be introduced into a finite element model in either of two general ways. In the first method called "discrete crack model", if conditions for cracking of an element occur, the element will be divided into two new elements parallel to the cracking plane. In the second method, the element will not be divided after cracking. Rather, cracking is accounted for by reducing the stiffness of the element. This is called the "smeared crack model" [12].

The discrete crack model requires re-meshing in process of the solution of the problem. That is why its computation cost is high and burdensome. Abdelbaky (2008) used this method for simulating debonding and obtained accurate results; the computations, however, had to be performed on a supercomputer [13].

Therefore, the discrete crack model is not usually used in the general modeling of a structure due to its associated costs and efforts. However, in some studies, while concrete cracks are treated as being smeared, a special element is used at the interface between the FRP sheet and the concrete which, under the predefined conditions, removes the relationship between degree of freedom of sheet and concrete elements, thereby introducing debonding into the model. In other words, the discrete crack model is used for a limited location in the structure. This method has been used in a number of studies including $\mathrm{Wu}$ and Hemdan (2004) [7] and $\mathrm{Lu}$ et al. (2007) [9]. Nevertheless, assuming discrete cracks even in limited sections of a structure 
will lead to high computation costs and will run into many numerical problems. Hence, some studies have suggested debonding to occur with reduced stiffness in elements at the interfacial layers [12] (smeared crack model). Hu et al. (2004) [14], Rahimi and Hutchinson (2001) [15], Aram et al. (2005) [16], and $\mathrm{Lu}$ and Ayoub (2010) [17] also used a similar method. Other methods, such as extended finite element (XFEM) and moving mesh technique, are the combination of smeared and discrete crack methods. These methods have been employed in a number of studies including Esna Ashari and Mohammadi (2011) [4] and Bruno et al. [5].

The methods commonly proposed for the simulation of debonding are complicated in most cases as they are developed based on complex mathematical concepts, making them inappropriate for solving engineering problems. In the present study, the physics of the problem is used to develop a method for simulating the debonding problem in the ABAQUS software package. Here, the process begins with the evaluation of the conditions and requirements for proper simulation of debonding. The capabilities of the ABAQUS software are then exploited to determine a method for proper modeling of debonding. In the proposed method, the method of smeared cracks is used to induce debonding the cohesive interface. The method is then validated by modeling four specimens reported in the literature for which numerical and experimental results are compared. The simplicity of the proposed method makes it especially suitable not only for solving engineering problems, but also for conducting case studies. The study is then supplemented with investigating the effects of the length and width of the strengthening plate on the behavior of strengthened beams as well as on the load and displacement of the debonding event.

\section{The proposed debonding simulation method}

Based on the aforementioned discussion, two major conditions are required for simulating the debonding failure within the framework of a finite element approach. First, the stresses exerted on the interfacial layer causing interfacial cracking which must be properly introduced into the finite element model. Second, the behavior of the interfacial layer against these stresses must be realistically considered, and the interfacial cracks must be formed in a timely manner. Below, we will investigate the methods used to meet these conditions.

As previously mentioned, stresses leading to intermediate debonding failure will give rise to flexural or flexural-shear cracking. Therefore, if crack opening occurs in its realistic proper manner, the stresses exerted on the interfacial layer will also follow a realistic pattern. Abdelbaky [13] maintained that the size of selected element must be three times smaller than the average aggregate size in order to ensure the validity of the FE-based simulation of crack opening in concrete based on smeared crack approach. The study reported in [18] indicates that there is no need for any special provisions to be made, since the stresses are concentrated on plate end which cause the debonding failure to have already been introduced into 3D FE models, in which volume elements are employed.

The requirements for the second condition are more complicated. The study reported in [19] indicates that this condition will not hold true for FE models used for simulating concrete behavior based on smeared cracking and that in such cases, special provisions must be made for interfacial crack formation. The reason for this lies in the dependence of interfacial cracking on concrete microstructure properties. In other words, interfacial cracking is a function of the microscopic properties of concrete and its microstructure, while the parameters used in FE-based simulation of concrete in smeared crack modeling, including cracking stress, compressive stress-strain curve, etc., are all macroscopic properties. Naturally, FE analysis is not capable of simulating concrete microscopic properties; hence, it fails to simulate those phenomena which arise from concrete microstructure properties.

Based on the above considerations, simulation of debonding failure in the normal FE analysis of concrete requires the interfacial layer behavior to be included in the calculations independent of concrete behavior. To put it differently, rather than the conventional modeling of the interfacial layer including the epoxy and the few millimeters of the immediately adjacent concrete (i.e., the concrete thickness peeling off with the FRP sheet), an element must be used whose behavior corresponds to the realistic situation. This objective can be realized by using an element in the software, called the cohesive element, which defines the behavior of two surfaces with respect to each other [20].

\subsection{Behavior of interfacial layer}

The true cause of the intermediate debonding failure may be attributed to the considerable shear stress created at the interfacial layer due to crack opening. Hence, the behavior of the interfacial layer under shear stress must be investigated for simulation purposes. The most important aspect of this behavior is the relationship between the shear stress $(\tau)$ and the relative displacement between the plate and the interfacial layer $(s)$ called slip.

Shear bond tests can be used to determine this relationship [2]. Based on statistical analyses of similar test results, researchers have proposed different models 


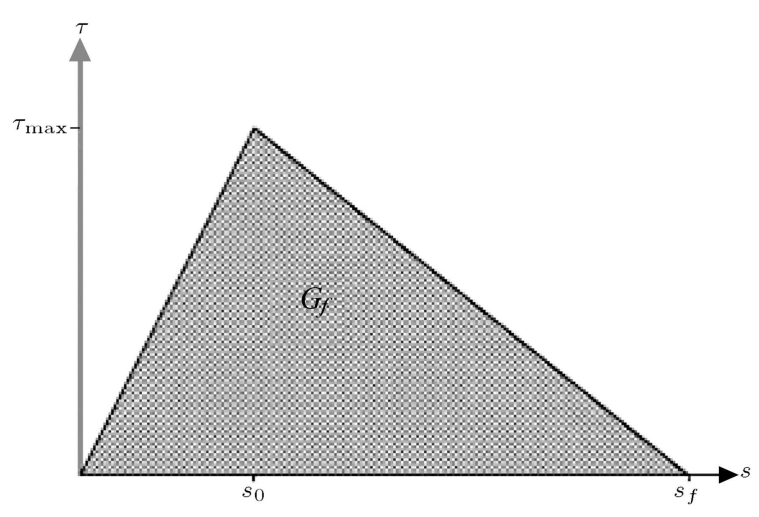

Figure 3. $\tau-s$ linear relationship.

for capturing this relationship. All these models generally comprise an ascending and a descending branches. Evidently, the ascending branch belongs to the pre-debonding state and the descending one belongs to the debonding initiation and completion state. Thus, $\tau-s$ relationship may be defined by four principal parameters that include: maximum shear stress $\left(\tau_{\max }\right)$, debonding initiation slip $\left(s_{0}\right)$, ultimate slip $\left(s_{f}\right)$, and the fracture energy per unit area $\left(G_{f}\right)$. Figure 3 illustrates these parameters for a bilinear relationship.

In this paper, the relations proposed by $\mathrm{Lu}$ et al. [12] are used and according to Abdelbaky [13] and Saxena [18], they are more accurate than their counterparts. These relations can be written as follows:

$$
\begin{aligned}
& \tau=\tau_{\max }\left(\frac{s}{s_{0}}\right) \quad \text { if } \quad s \leq s_{0}, \\
& \tau=\tau_{\max }\left(\frac{s_{f}-s}{s_{f}-s_{0}}\right) \quad \text { if } \quad s>s_{0}, \\
& \tau_{\max }=1.5 \beta_{w} f_{t}, \\
& s_{0}=0.0195 \beta_{w} f_{t}, \\
& G_{f}=0.308 \beta_{w}^{2} \sqrt{f_{t}}, \\
& s_{f}=\frac{2 G_{f}}{\tau_{\max }}, \\
& \beta_{w}=\sqrt{\frac{\left(2.25-\frac{b_{p}}{b_{c}}\right)}{\left(1.25+\frac{b_{p}}{b_{c}}\right)}}
\end{aligned}
$$

where $f_{t}, b_{c}, b_{p}$ are concrete cracking stress, concrete beam width, and plate width, respectively. Note that slip is expressed in $\mathrm{mm}$, stress in $\mathrm{MPa}$, and fracture energy per unit area is expressed in $\mathrm{N} / \mathrm{mm}$.

\subsection{Cohesive elements and appropriate values of the relevant parameters}

Cohesive elements are located between two different surfaces and cause stresses on the surfaces in contact due to slips. An important property of such elements is that they can be used to develop an explicit relation between the stress created and the relative displacement (slip) of surfaces. Moreover, this element is capable of modeling the debonding failure between surfaces.

Clearly, two different surfaces in contact may move relatively to each other either in a vertical or in two parallel directions. When moving in the vertical direction, the two surfaces induce a normal stress on each other, while they induce a shear stress when moving in two parallel directions. That is why cohesive elements parameters may be defined in three independent directions. The stress-displacement relation in the linear mode may be written as follows [20]:

$$
\left\{\begin{array}{l}
t_{n}=k_{n n} \delta_{n} \\
t_{s}=k_{s s} \delta_{s} \\
t_{t}=k_{t t} \delta_{t}
\end{array}\right.
$$

where $\delta_{n}, \delta_{s}$, and $\delta_{t}$ represent relative displacements in the vertical and two parallel directions, respectively; $t_{n}, t_{s}$, and $t_{t}$ designate normal stress and shear stresses created due to relative displacements. The unit vector in the direction of $n$ will be obtained from the external product of the unit vector in the direction of $s$ by the unit vector in the direction of $t$. It must be mentioned that for the purposes of the present study, the plate is modeled in a manner that the direction of the fibers is in the direction of $s$; consequently, the interfacial layer will be normal to $n$ (Figure 4).

The value of $k_{s s}$ represents the slope of the pre-debonding shear stress-displacement curve; this parameter is introduced into Eq. (1) in accordance with Lu's relation and is determined as follows:

$$
k_{s s}=\frac{\tau_{\max }}{s_{0}} .
$$

There is little research reported on the behavior $t$ direction (perpendicular to fibers), since insignificant shear stresses actually developed in this direction and so have little impact on the general behavior of the

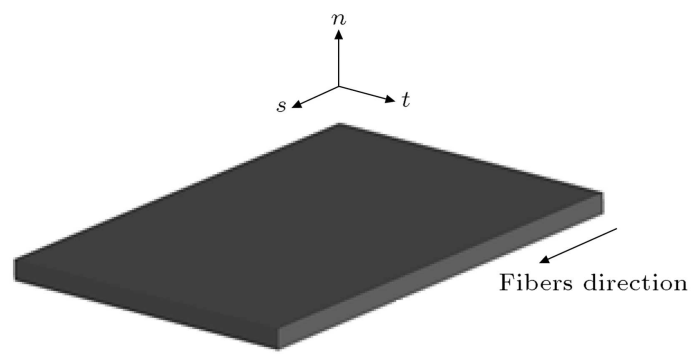

Figure 4. $t, n$, and $s$ directions. 
model. Hence, we have assumed its behavior to be similar to the $s$ direction.

In calculations, the thicknesses of the cohesive elements are assumed to be equal to unity regardless of their geometric thicknesses [20]. Therefore, the strain in the normal direction will be equal to the vertical displacement and will be defined as follows:

$$
\varepsilon_{n}=\frac{\delta_{n}}{t}
$$

Thus, in the calculation of cohesive elements, relative displacement in the direction of $n\left(\delta_{n}\right)$ is the same as axial strain in the direction of $n\left(\varepsilon_{n}\right)$. Therefore, $k_{n n}$ represents the slope of the interfacial layer stressaxial strain prior to cracking. According to Coronado, behavior in this direction is directly evaluated based on concrete behavior [2]; consequently, the value for $k_{n n}$ will be equal to that of concrete modulus of elasticity.

Obviously, Eq. (2) is linear up to deboning initiation; after that, it will no longer be linear as shown in Figure 3, stress will reduce with increasing displacement between the two surfaces. At the point of ultimate displacement, stress will become nil and two surfaces will be completely separated.

In order to account for debonding in the calculations, it will be necessary to define two sets of parameters for cohesive elements. The first set will define the criteria for debonding initiation, while the second set will determine its development and completion [20]. The first set of parameters indeed describes the condition before which a linear behavior prevails, and it is followed by a descending zone in the shearslip curve when debonding initiates. Using Eq. (1), this situation may be defined as follows:

$$
\left\{\begin{array}{l}
\frac{\leq t_{n}>}{t_{n}^{0}}=1 \\
\frac{\left|t_{t}\right|}{t_{t}^{0}}=1 \\
\frac{\left|t_{s}\right|}{t_{s}^{0}}=1
\end{array}\right.
$$

The above equation indicates that the debonding process in each direction initiates only when the exerted stress in that direction reaches its maximum value specified by the user [20]. In Eq. (5), $t_{n}, t_{t}$, and $t_{s}$, respectively, represent the maximum stress values specified in the normal and shear directions, and Mackulay bracket \langle\rangle is defined as $\left\langle t_{n}\right\rangle=\left(t_{n}+\left|t_{n}\right|\right) / 2$ [20]. The reason for using this operator is that the two surfaces do not detach under vertical pressure. It is clear that the interaction effect of normal and shear stresses is not considered, and the criterion used is, therefore, an uncoupled one.

According to Lu's model, the values for $t_{s}^{0}$ and $t_{t}^{0}$ will be equal to $\tau_{\max }$ in Eq. (1). As already mentioned and according to Coronado [2], the behavior of the interfacial layer in the normal direction will be in accordance with concrete behavior. Therefore, the value taken for $t_{n}^{0}$ must be equal to concrete cracking stress.

A parameter must also be defined for measuring the reduced stiffness of the element after debonding. Either of the two parameters of relative displacement or work done by the interfacial stresses in the software may be exploited for this purpose. In the present study, the work done by the interfacial stresses based on Eq. (2) has been used. In this case, the element's stiffness is reduced in proportion to the work done by the interfacial stresses until the work reaches the value defined by the user for fracture energy [20]. Evidently, the interfacial fracture energy which is equal to the area under the stress-slip curve needs to be defined. The fracture energy may be independently defined for each of the three directions. Based on these observations, it is clear that fracture energy in $t$ and $s$ directions will be determined from Eq. (1d), and the fracture energy of concrete under tension which is equal to the area under the stress-tensile strain curve will be obtained from the following relation [20]:

$$
G_{f}^{c}=\frac{5 f_{t}^{2}}{E_{c}},
$$

where $f_{t}$ and $E_{c}$ are the concrete cracking stress and modulus of elasticity, respectively.

\section{Validity of the proposed approach}

To verify the validity and practicability of the proposed approach in flexurally strengthened RC beams, four specimens were selected from the existing literature. These specimens were introduced by the Swiss Federal Lab in 1996 and reported in [16], Rahimi and Hutchinson in 2001 [15], Wu and Kurokawa in 2002 [21], and Yao in 2004 [22]. The specimens prepared by Rahimi and Hutchinson and the Swiss Federal Lab had been subjected to the four-point bending test, while that of $\mathrm{Wu}$ had been subjected to three-point bending test, and that of Yao had been subjected to cantilever loading test. The geometrical and material specifications of the specimens are summarized in Tables 1 to 4 and are presented in Figures 5 to 9 . The non-linear behavior of concrete, such as cracking and confinement, has been accounted for using Lee and Fenves's theory which is available in the materials library of the software used [20].

The Modified Hognestad Relation is employed for the stress-strain curve of concrete under pressure (Figure 10(a)). Using these equations, the concrete stress-strain curve is obtained in terms of concrete compressive strength $\left(f_{c}^{\prime}\right)$ and the corresponding strain $\left(\varepsilon_{0}\right)$ as in Eq. (7) [23]: 


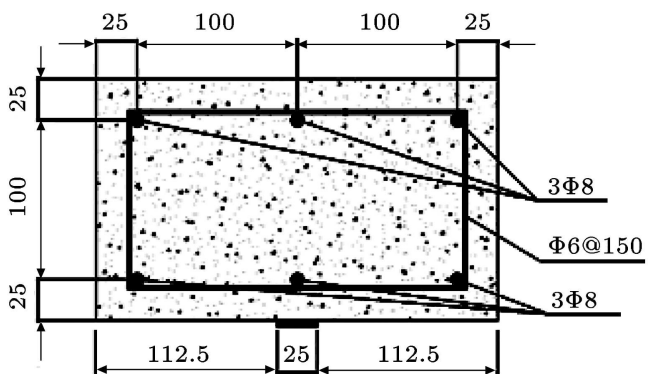

(a)

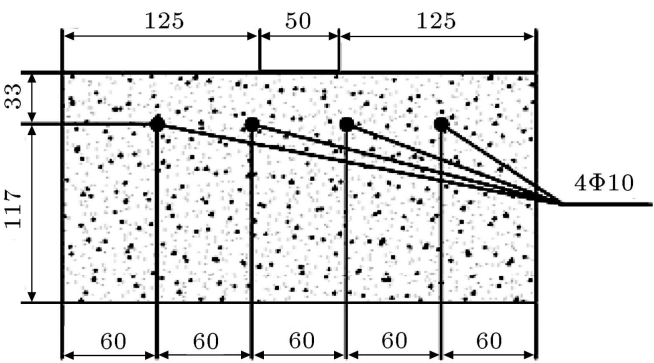

(c)

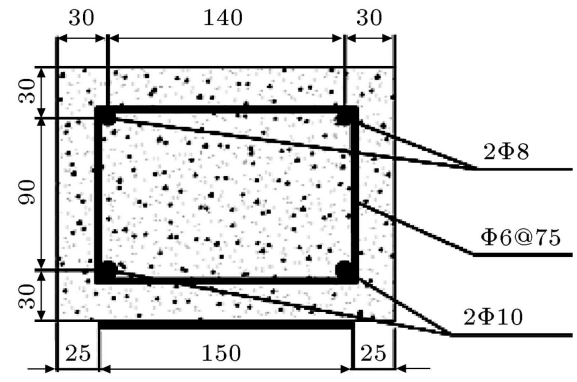

(b)

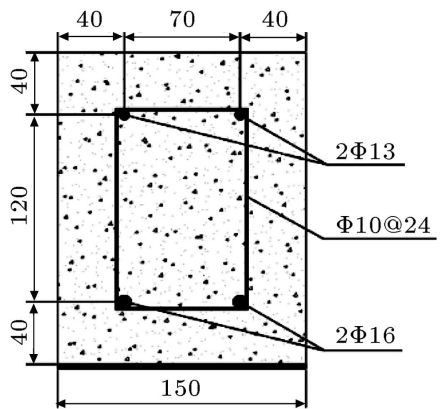

(d)

Figure 5. Cross section of (a) Swiss Federal Lab specimen [16], (b) Rahimi's specimen [15], (c) Wu's specimen [21], and (d) Yao's specimen [22] (in mm).

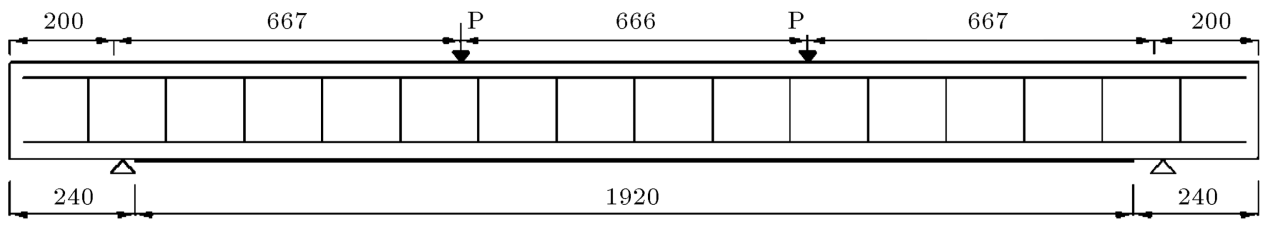

Figure 6. Longitudinal section of Swiss Federal Lab's specimen (in mm) [16].

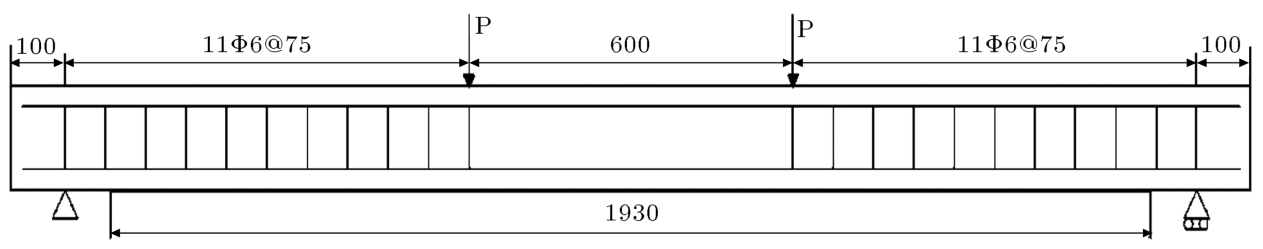

Figure 7. Longitudinal section of Rahimi's specimen (in mm) [15].

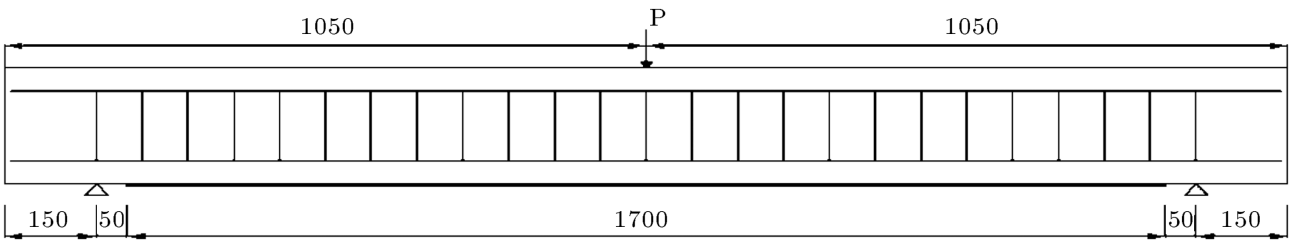

Figure 8. Longitudinal section of Wu's specimen (in mm) [21].

$$
f_{c}= \begin{cases}f_{c}^{\prime}\left[\frac{2 \varepsilon_{c}}{\varepsilon_{0}}-\left(\frac{\varepsilon_{c}}{\varepsilon_{0}}\right)^{2}\right] & \varepsilon_{c} \leq \varepsilon_{0} \\ f_{c}^{\prime}\left[1-0.15\left(\frac{\varepsilon_{c}-\varepsilon_{0}}{\varepsilon_{c u}-\varepsilon_{0}}\right)\right] & \varepsilon_{c}>\varepsilon_{0}\end{cases}
$$

where $\varepsilon_{c u}$ is the ultimate strain of concrete under com- pression, which is assumed to be equal to 0.0038 [23]. $\varepsilon_{0}$ can be obtained from the following equation:

$$
\varepsilon_{0}=2 \frac{f_{c}^{\prime}}{E_{c}}
$$

where $E_{c}$ is the Modulus of elasticity of concrete. Ac- 
Table 1. Geometric specification of simulated specimens.

\begin{tabular}{cccccccccc}
\hline $\begin{array}{c}\text { Shear } \\
\text { steel }\end{array}$ & $\begin{array}{c}\text { Compressive } \\
\text { steel }\end{array}$ & $\begin{array}{c}\text { Tensile } \\
\text { steel }\end{array}$ & $\begin{array}{c}\text { Plate } \\
\text { thickness } \\
(\mathbf{m m})\end{array}$ & $\begin{array}{c}\text { Plate } \\
\text { width } \\
(\mathbf{m m})\end{array}$ & $\begin{array}{c}\text { Plate } \\
\text { length } \\
(\mathbf{m m})\end{array}$ & $\begin{array}{c}\text { Height } \\
(\mathbf{m m})\end{array}$ & $\begin{array}{c}\text { Width } \\
(\mathbf{m m})\end{array}$ & $\begin{array}{c}\text { Length } \\
(\mathbf{m m})\end{array}$ & Specimen \\
\hline$\Phi 6 @ 150$ & $3 \Phi 8$ & $3 \Phi 8$ & 1.2 & 50 & 1960 & 150 & 250 & 2400 & Federal $[16]$ \\
$\Phi 6 @ 75$ & $2 \Phi 8$ & $2 \Phi 10$ & 1.8 & 150 & 1930 & 200 & 150 & 2300 & Rahimi $[15]$ \\
$\Phi 10 @ 24$ & $2 \Phi 13$ & $2 \Phi 16$ & 0.11 & 150 & 1700 & 200 & 150 & 2100 & Wu $[21]$ \\
- & - & $4 \Phi 10$ & 1.2 & 50 & 1000 & 150 & 300 & 1100 & Yao $[22]$ \\
\hline
\end{tabular}

Table 2. Specification of concrete used in simulated specimens.

\begin{tabular}{cccc}
\hline $\begin{array}{c}\text { Cracking stress } \\
(\mathbf{M P a})\end{array}$ & $\begin{array}{c}\text { Compressive strength } \\
(\mathbf{M P a})\end{array}$ & $\begin{array}{c}\text { Modulus of elasticity } \\
(\mathbf{G P a})\end{array}$ & Specimen \\
\hline 3.4 & 39.2 & 27.5 & Federal [16] \\
4.0 & 43 & 25.07 & Rahimi [15] \\
4.5 & 49.3 & 35.1 & $\mathrm{Wu}[21]$ \\
2.8 & 27 & 22.81 & Yao $[22]$ \\
\hline
\end{tabular}

Table 3. Specification of steel reinforcement used in simulated specimens.

\begin{tabular}{|c|c|c|c|c|}
\hline $\begin{array}{c}\text { Ultimate } \\
\text { strain (\%) }\end{array}$ & $\begin{array}{c}\text { Ultimate } \\
\text { stress (MPa) }\end{array}$ & $\begin{array}{c}\text { Yielding } \\
\text { stress (MPa) }\end{array}$ & $\begin{array}{c}\text { Modulus of } \\
\text { elasticity (GPa) }\end{array}$ & Specimen \\
\hline 12 & 623 & 485 & 210 & Federal [16] \\
\hline 5.25 & 775 & 575 & 210 & Rahimi [15] \\
\hline 6 & 546 & 364 & 210 & $\mathrm{Wu}[21],(\Phi 16)$ \\
\hline 6 & 537 & 358 & 210 & $\mathrm{Wu}[21],(\Phi 13)$ \\
\hline 16 & 543 & 343 & 208 & Yao [22] \\
\hline
\end{tabular}

Table 4. Specifications of strengthening plate used in simulated specimens.

\begin{tabular}{cccc}
\hline $\begin{array}{c}\text { Rupture strain } \\
(\text { micro) }\end{array}$ & $\begin{array}{c}\text { Tensile strength } \\
(\mathbf{M P a})\end{array}$ & $\begin{array}{c}\text { Modulus of elasticity } \\
(\mathbf{G P a})\end{array}$ & Specimen \\
\hline 17400 & 2700 & 155 & Federal [16] \\
29800 & 1074 & 36 & Rahimi [15] \\
17800 & 4100 & 230 & $\mathrm{Wu}[21]$ \\
18600 & 2800 & 150 & Yao $[22]$ \\
\hline
\end{tabular}

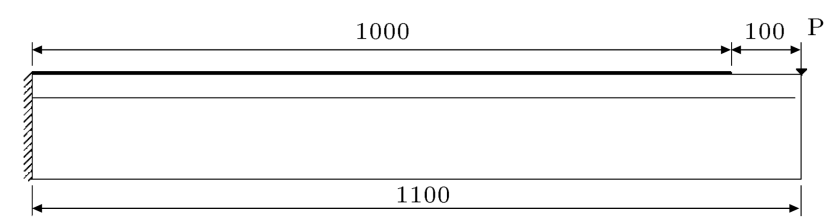

Figure 9. Longitudinal section of Yao's specimen (in $\mathrm{mm})[22]$.

cording to ACI 318 Code, in cases where no empirical data are available, the value of $E_{c}$ can be obtained from Eq. (9) [24]:

$$
E_{c}=4700 \sqrt{f_{c}^{\prime}} \text {. }
$$

The stress-strain curve under tension consists of the two rising and falling branches, as shown in Figure $10(\mathrm{~b})$, which represent the states before and after cracking, respectively. Clearly, stress does not abruptly fall into zero after cracking, but it takes a gradually reducing trend. This property, called 'tension stiffening', is due to the friction among aggregates, their interlocking, and the dowel action of longitudinal bars [25].

The moduli of elasticity for concrete under compression and tension are equal [10]; consequently, the slope of ascending branch of the tensile stress-strain curve can be obtained from Eq. (9). According to the ACI 318 Code, the modulus of rupture of concrete can be obtained from the following relation [24]:

$$
f_{r}=0.62 \sqrt{f_{c}^{\prime}}
$$

The value considered for the tensile strain, at which the concrete tensile stress becomes zero, will be equal 


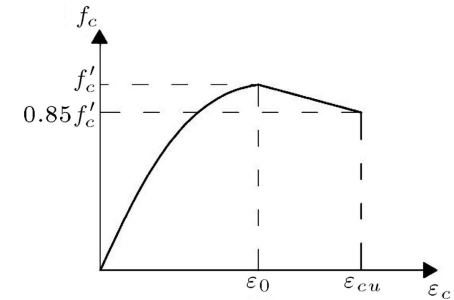

(a)

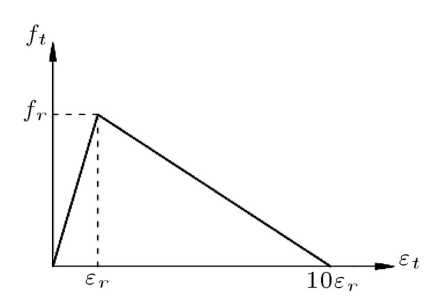

(b)

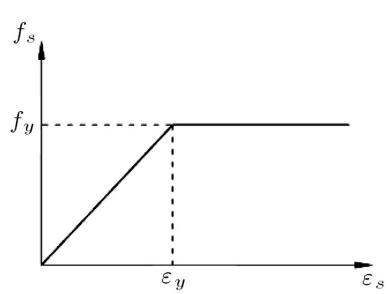

(c)

Figure 10. Schematic representations of the stress-strain curves used: (a) For concrete under compression, (b) for concrete under tension, and (c) for longitudinal steel.

to 10 times the cracking strain, as it is demonstrated in Figure 10(b) [26].

Based on the classic theories used for RC structural analysis and design, a full elastic-plastic regime is adopted for the stress-strain curve of steel. In other words, up to the yield strain, this curve will take a linear form with a slope equal to that of the modulus of elasticity of steel. And, beyond this point, stress will become constant and equal to yield stress (Figure 10(c)). Table 3 presents the mechanical characteristics of the steel rebars used in the specimens [15,16,21,22].

The stress-strain curves for FRP plates are linear up to the failure point [27]. Given the fact that failure modes of all the four specimens are the debonding of the strengthening plate, and plate rupture was not observed in any of the specimens, the behavior of this material is considered to be a linear elastic one; hence, its failure is not included in the numerical model. It is, therefore, necessary to make sure that the strain created in the strengthening plate along the fiber direction is lower than its rupture strain. Table 4 presents the mechanical characteristics of the strengthening plates used in the specimens.

For modeling the concrete beam, steel plates, and FRP sheets, 8-node brick elements (with 24 DOFs) were used, while truss elements were utilized for longitudinal reinforcement and steel ties. The NewtonRaphson method was used for the solution of nonlinear equations. It must be noted that as 8-node brick elements are used in this paper, degrees of freedom shall only include displacements (translational degrees of freedom), so that rotations are not included in freedom degrees. Accordingly, creation of joint supports will require translational degrees of freedom to be bound to a single line. In this paper, the displacements on the edges of support plates were bound to create joint supports and all the DOFs of the lateral side were bound to create fixed supports. The interfacial layer was modeled using cohesive.

Based on what was mentioned above about meshing, efforts were made to use cubic elements of $25 \times 25 \times$ $25 \mathrm{~mm}$ in all the specimens. As for the plate and adhesive, cubic elements with a side of $25 \mathrm{~mm} \times 25 \mathrm{~mm} \times$ thickness of plate, respectively, were used.

The dimensions of the elements at the loading point and the support location were different from those of other positions due to geometrical considerations. The dimensions of the elements used in these locations are presented in Table 5 in order of $x, y$, and $z$ directions. For instance, $19 \times 20 \times 12.5$ will be a cube $19 \mathrm{~mm}$ long in the $x$ direction, $20 \mathrm{~mm}$ wide in the $y$ direction, and $12.5 \mathrm{~mm}$ in the $z$ direction. Beam's length is parallel to $x$, and depth of cross section is parallel to $z$ direction.

The experimental and analytical results obtained are compared in Figures 11 to 14 and in Tables 6

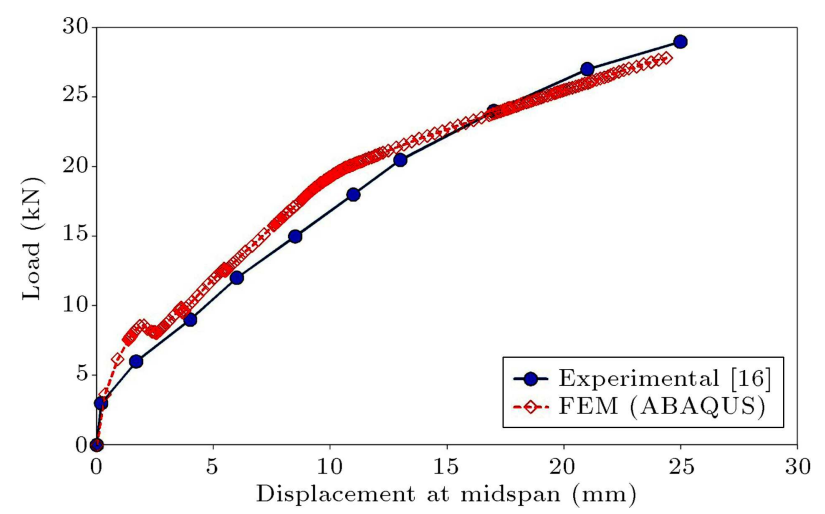

Figure 11. Comparison of experimental and analytical load-displacement curves for Swiss Federal Lab specimen.

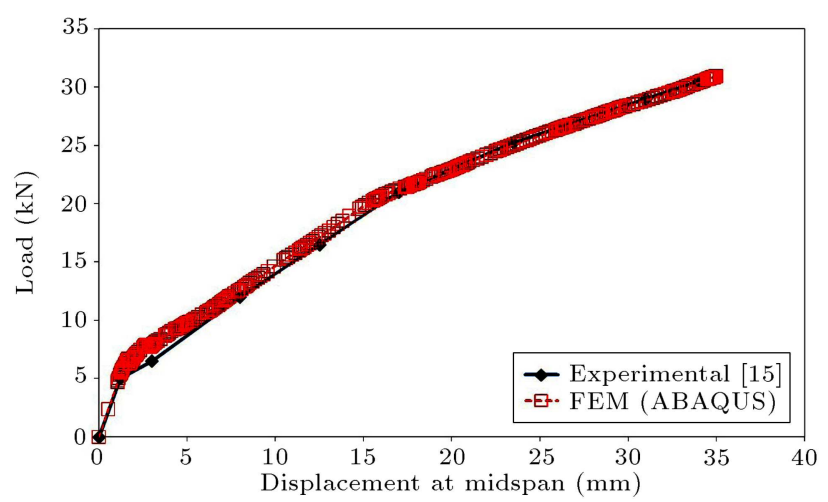

Figure 12. Comparison of experimental and analytical load-displacement curves for Rahimi's specimen. 
Table 5. Dimensions of elements used under special geometric conditions.

\begin{tabular}{cccccc}
\hline \multicolumn{2}{c}{$\begin{array}{c}\text { Dimensions of plate and } \\
\text { cohesive elements at } \\
\text { the loading site }(\mathbf{m m})\end{array}$} & & \multicolumn{2}{c}{$\begin{array}{c}\text { Dimensions of } \\
\text { concrete elements }(\mathbf{m m})\end{array}$} & Specimen \\
\cline { 1 - 2 } \cline { 5 - 6 } Cohesive elements & Plate elements & & At support point & At loading site & \\
\hline $25 \times 0.5 \times 20$ & $25 \times 1.2 \times 20$ & & $20 \times 19 \times 20$ & $20 \times 19 \times 20$ & Federal $[16]$ \\
$25 \times 2 \times 25$ & $25 \times 0.6 \times 25$ & & $25 \times 25 \times 10$ & $25 \times 25 \times 20$ & Rahimi $[15]$ \\
$19 \times 0.5 \times 20$ & $19 \times 0.111 \times 20$ & & $19 \times 20 \times 12.5$ & $19 \times 20 \times 12.5$ & Wu $[21]$ \\
- & - & $25 \times 25 \times 20$ & $25 \times 25 \times 20$ & Yao [22] \\
\hline
\end{tabular}

Table 6. Experimental results for simulated specimens.

\begin{tabular}{|c|c|c|c|c|c|}
\hline \multirow[t]{2}{*}{$\begin{array}{l}\text { Plate strain } \\
\text { (micro) }\end{array}$} & \multicolumn{2}{|c|}{$\begin{array}{c}\text { Load and displacemen } \\
\text { corresponding to yielding point } \\
\text { of tensile steel }\end{array}$} & \multicolumn{2}{|c|}{$\begin{array}{l}\text { Load and displacement } \\
\text { corresponding to failure }\end{array}$} & \multirow[t]{2}{*}{ Specimen } \\
\hline & $\begin{array}{c}\text { Displacement } \\
(\mathbf{m m})\end{array}$ & $\begin{array}{l}\text { Load } \\
(\mathrm{kN})\end{array}$ & $\begin{array}{l}\text { Displacement } \\
(\mathrm{mm})\end{array}$ & $\begin{array}{l}\text { Load } \\
(\mathrm{kN})\end{array}$ & \\
\hline 7640 & 9 & 19.5 & 25 & 29.5 & Federal [16] \\
\hline 10100 & 15.5 & 21 & 34 & 30.5 & Rahimi [15] \\
\hline 16600 & 5.5 & 58 & 19 & 79 & $\mathrm{Wu}[21]$ \\
\hline 5420 & 14.1 & 9.2 & 18.84 & 19.62 & Yao [22] \\
\hline
\end{tabular}

Table 7. Numerical results for simulated specimens.

\begin{tabular}{|c|c|c|c|c|c|}
\hline \multirow[t]{2}{*}{$\begin{array}{l}\text { Plate strain } \\
\quad \text { (micro) }\end{array}$} & \multicolumn{2}{|c|}{$\begin{array}{c}\text { Load and displacement correspondin } \\
\text { to yielding point of } \\
\text { tensile steel }\end{array}$} & \multicolumn{2}{|c|}{$\begin{array}{l}\text { Load and displacement } \\
\text { corresponding to failure }\end{array}$} & \multirow[t]{2}{*}{ Specimen } \\
\hline & $\begin{array}{c}\text { Displacement } \\
(\mathbf{m m})\end{array}$ & $\begin{array}{l}\text { Load } \\
(\mathrm{kN})\end{array}$ & $\begin{array}{c}\text { Displacement } \\
(\mathrm{mm})\end{array}$ & $\begin{array}{l}\text { Load } \\
(\mathrm{kN})\end{array}$ & \\
\hline 7419 & 8.27 & 18.13 & 24.38 & 28.65 & Federal [16] \\
\hline 9742 & 14.49 & 20.19 & 33.17 & 30.77 & Rahimi [15] \\
\hline 16870 & 5.25 & 57.03 & 22.16 & 79.98 & Wu [21] \\
\hline 5517 & 13.68 & 8.95 & 19.11 & 18.18 & Yao $[22]$ \\
\hline
\end{tabular}

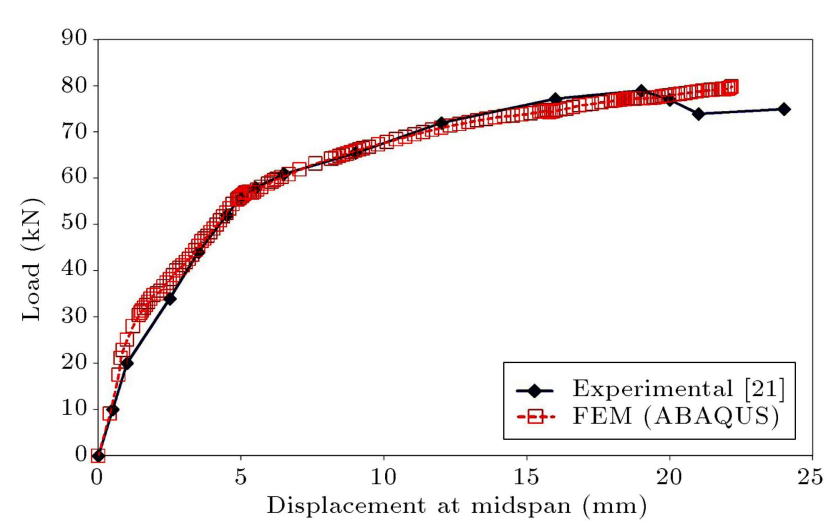

Figure 13. Comparison of experimental and analytical load-displacement curves for Wu's specimen.

and 7. Clearly, these two sets of results are in good agreement. Hence, the proposed model seems to be capable of predicting the failure mode and behavior

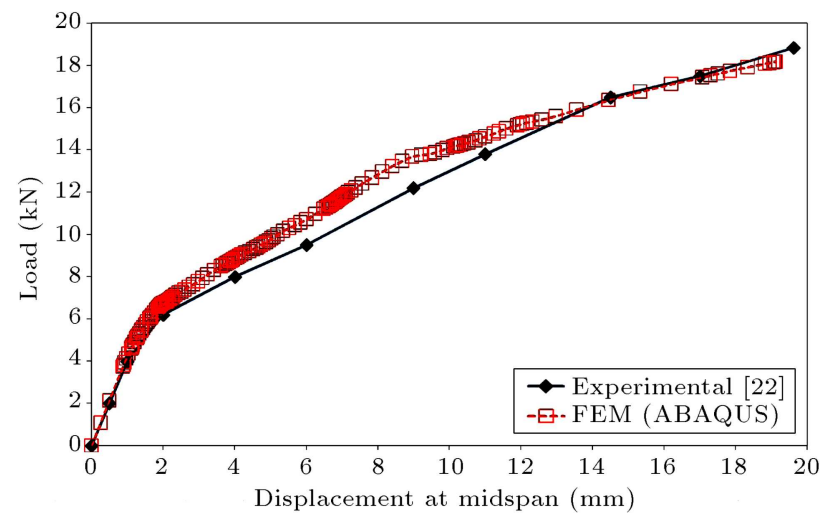

Figure 14. Comparison of experimental and analytical load-displacement curves for Yao's specimen.

of FRP strengthened RC beams. Figure 15 plots diagrams for interfacial shear stress along the plate during three cracking events, yielding point of tensile 


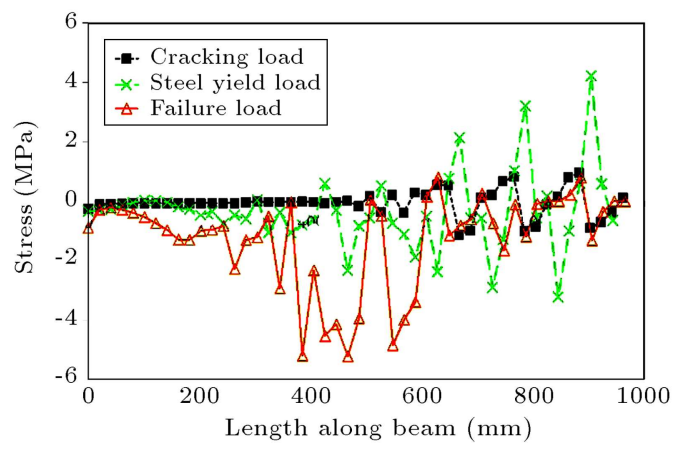

(a)

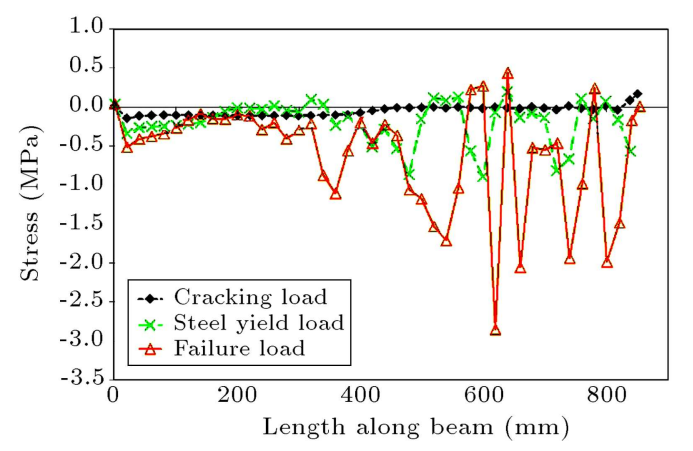

(c)

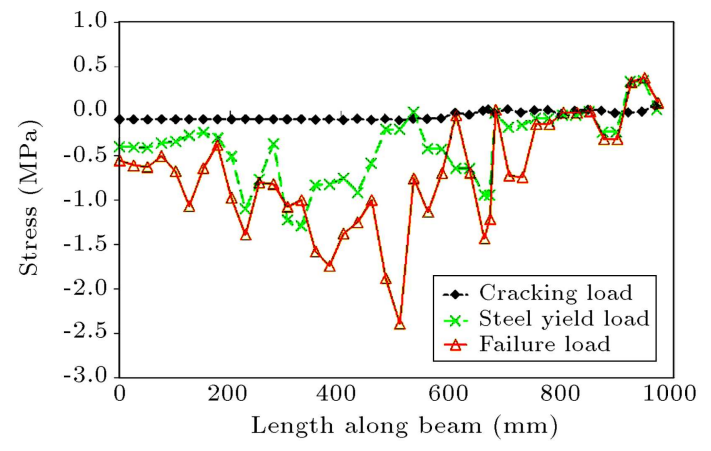

(b)

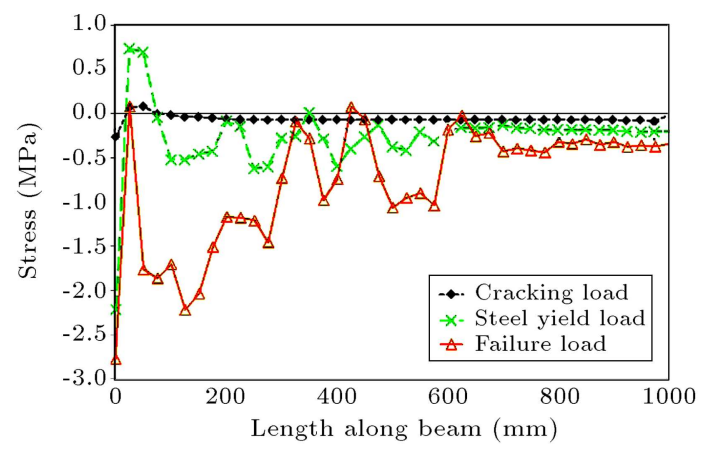

(d)

Figure 15. Shear stress variations along the line passing through the top surface of plate (the surface in contact with the concrete): (a) In the Federal's specimen [16], (b) in the Rahimi's specimen [15], (c) in the Wu's specimen [21], and (d) in Yao's specimen [22].

reinforcement, and failure for the Federal, Rahimi and Hutchinson, $\mathrm{Wu}$, and Yao specimens. In all these cases, except for the diagram in Figure 15(d), the length has been measured from the plate end. In the diagram in Figure 15(d) presenting Yao's cantilever specimen, length is measured from the fixed support point. It may then be concluded that concentration of shear stress was due to the opening of the cracks. A corollary of this observation is that the method used here has been valid and practicably correct, and that the concentration of the shear stress has been created due to the opening of cracks; the subsequent debonding has been properly introduced into the model.

Comparison of the strain at the ultimate state (debonding) and its rupture strain will show whether or not the plate ruptures. Table 7 presents the values for the strain in the numerical models at the debonding. Comparison of these strain values with plates rupture strains (Table 4) indicates that the plates do not undergo rupture prior to their debonding.

\section{Case studies}

Having ensured the validity of the proposed model and the acceptability of the results thus obtained, the effects of FRP plate length, width on the flexural behavior, and failure load of strengthened RC beams are investigated in this section. For this purpose, the specimen tested by Rahimi and Hutchinson [15] and Swiss Federal Lab [16] was selected from those among which the model was verified by earlier. The used procedure involves varying only one parameter of interest in each of the selected specimens; the specimen is then modeled along the lines described in the previous section; finally, the relevant analyses are implemented.

\subsection{Investigation of effect of plate length variations}

Yao investigated plate length variation and concluded that increasing plate length increases the ultimate load and the corresponding displacement; however, it had no impact on the overall trend of load-displacement curve [22]. In the present study, the effect of FRP plate length on failure load and flexural behavior of strengthened beam was investigated using five different plate lengths for each specimen. The specifications of the specimens used here for modeling are exactly those presented in Tables 1 to 4 . The only difference lies in their plate length presented in Table 1 for modeling purposes; it will, therefore, suffice to change plate lengths in the models already developed. The modeling results for each specimen are presented in Tables 8 and 9. In these tables, the moment percentage is defined as the ratio of flexural moment at the plate cutoff location to maximum flexural moment multiplied by 
Table 8. Effects of plate length variation on behavior for Rahimi's specimen.

\begin{tabular}{|c|c|c|c|c|c|c|}
\hline \multirow[t]{2}{*}{$\begin{array}{c}\text { Max plate } \\
\text { stress (MPa) }\end{array}$} & \multicolumn{2}{|c|}{$\begin{array}{c}\text { Load and displacement } \\
\text { corresponding to yielding point } \\
\text { of tensile steel }\end{array}$} & \multicolumn{2}{|c|}{$\begin{array}{l}\text { Load and displacement } \\
\text { corresponding to failure }\end{array}$} & \multirow[t]{2}{*}{$\begin{array}{c}\text { Moment } \\
\text { percentage }\end{array}$} & \multirow[t]{2}{*}{$\begin{array}{l}\text { Plate length } \\
\qquad(\mathrm{mm})\end{array}$} \\
\hline & $\begin{array}{c}\text { Displacement } \\
(\mathbf{m m})\end{array}$ & $\begin{array}{l}\text { Load } \\
(\mathrm{kN})\end{array}$ & $\begin{array}{l}\text { Displacement } \\
(\mathrm{mm})\end{array}$ & $\begin{array}{l}\text { Load } \\
(\mathrm{kN})\end{array}$ & & \\
\hline 149 & 15.45 & 20.38 & 15.55 & 20.50 & 40.00 & 1500 \\
\hline 239.5 & 15.37 & 20.28 & 23.83 & 25.71 & 33.33 & 1600 \\
\hline 272.0 & 14.69 & 20.34 & 27.82 & 27.20 & 26.67 & 1700 \\
\hline 314.6 & 14.52 & 20.36 & 30.39 & 30.13 & 20.00 & 1800 \\
\hline 340.5 & 14.49 & 20.19 & 33.17 & 30.77 & 11.33 & 1930 \\
\hline
\end{tabular}

Table 9. Effects of plate length variation on behavior for Swiss Federal's specimens.

\begin{tabular}{|c|c|c|c|c|c|c|}
\hline \multirow[t]{2}{*}{$\begin{array}{c}\text { Max plate } \\
\text { stress (MPa) }\end{array}$} & \multicolumn{2}{|c|}{$\begin{array}{c}\text { Load and displacement } \\
\text { corresponding to yielding point } \\
\text { of tensile steel }\end{array}$} & \multicolumn{2}{|c|}{$\begin{array}{l}\text { Load and displacement } \\
\text { corresponding to failure }\end{array}$} & \multirow[t]{2}{*}{$\begin{array}{c}\text { Moment } \\
\text { percentage }\end{array}$} & \multirow[t]{2}{*}{$\begin{array}{l}\text { Plate length } \\
(\mathbf{m m})\end{array}$} \\
\hline & $\begin{array}{c}\text { Displacement } \\
(\mathrm{mm})\end{array}$ & $\begin{array}{l}\text { Load } \\
(\mathrm{kN})\end{array}$ & $\begin{array}{l}\text { Displacement } \\
(\mathrm{mm})\end{array}$ & $\begin{array}{l}\text { Load } \\
(\mathrm{kN})\end{array}$ & & \\
\hline 726 & 8.14 & 18.27 & 14.83 & 23.76 & 40.00 & 1466 \\
\hline 891 & 8.52 & 18.25 & 19.22 & 25.94 & 33.33 & 1556 \\
\hline 926 & 8.64 & 18.51 & 20.38 & 26.55 & 26.67 & 1646 \\
\hline 1006 & 8.90 & 18.67 & 21.78 & 26.85 & 20.00 & 1734 \\
\hline 1144 & 8.27 & 18.13 & 24.38 & 28.65 & 6.00 & 1920 \\
\hline
\end{tabular}

100 ; and the displacement is referred to as the midspan displacement.

Effect of plate length on load-displacement curves for the specimens modeled is plotted in Figure 16. As shown in the diagrams and also presented in Tables 8 and 9 , failure load and ultimate displacement increase with increasing plate length for specimens in which debonding dominates their failure mode. This parameter, however, has neither effect on the trend of the load-displacement curve nor on yield load of steel. It is observed that these results are in agreement with those reported by Yao [22].

Schematic loading arrangement of the beams is

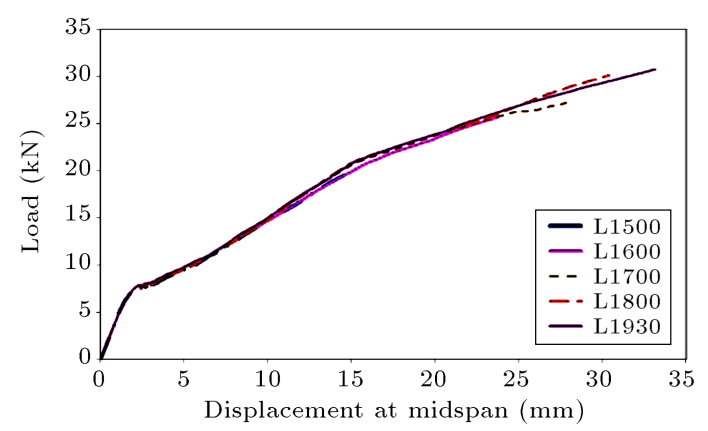

(a) plotted in Figure 17. It is evident that the flexural moment and shear force curves along the beam have no relationship with the ratios $\frac{E I_{1}}{E I_{2}}$ and $\frac{l_{1}}{l_{2}}$. Therefore, in all the specimens with different plate lengths, the location of the maximum bending moment and shear force is unchanged.

The inclined bending-shear crack forming under the loading point will be more critical than other cracks since both flexural moment and shear force are maximal at this point. A shear stress concentration will form in the interface between the plate and concrete due to the opening of this crack. Based on investigations by the Japanese Society of Civil

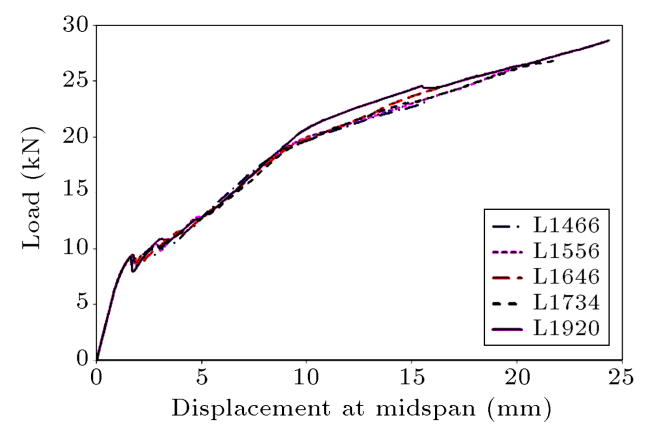

(b)

Figure 16. Effect of plate length variation on load-displacement curve: (a) In Rahimi's specimen, and (b) in Federal's specimen. 


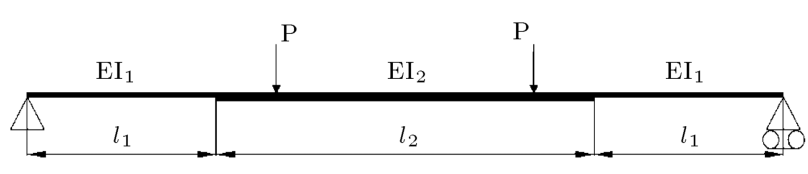

Figure 17. General conditions of the specimens tested.

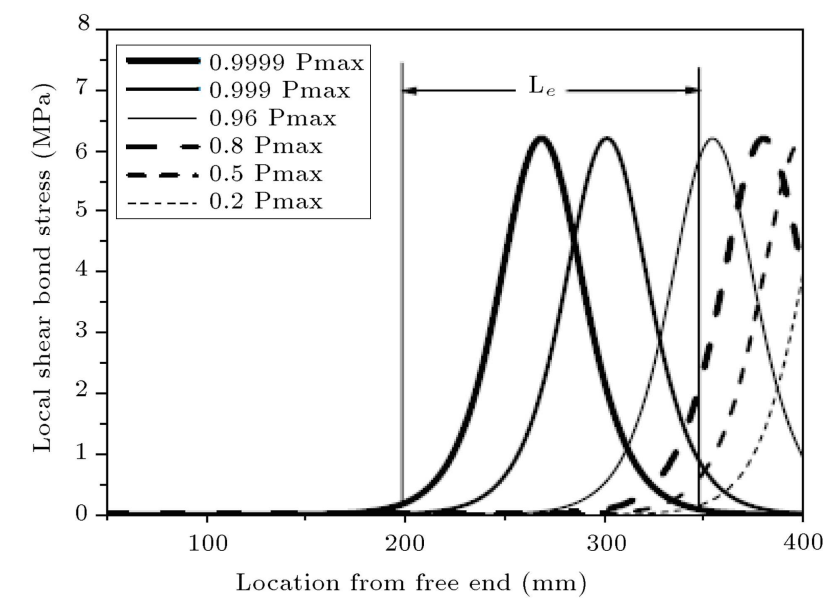

Figure 18. Shear stress concrete block [28].

Engineers, only a limited portion of surface area of the plate, rather than the whole surface area, plays a role in the transfer of this shear stress [28]. In other words, if the diagram of interfacial shear stress magnitude along the plate length is plotted, obviously the shear stress will have a considerable value only over a limited stretch of the plate length. This causes a shear stress block to be created at the interface between the concrete and the FRP plate.

This stress block is clearly seen in Figure 18 that illustrates the shear stress magnitude in a direct shear test [28]. A larger part of stress block will form when the plate length increases; consequently, the maximum of transferred shear stress will reduce at different stages of loading, leading to its ultimate value at higher loads. When this stress block takes full form after the plate reaches a certain length, increasing length will not have any great effect on the shear stress transferred; thereby, no considerable change will occur in the ultimate load.

\subsection{Investigation of effects of plate width changes}

It is unfortunate that no serious investigation has been reported in the literature on the effect of changes on plate width. However, numerous studies have been reported on investigation of plate axial stiffness (i.e., the product of modulus of elasticity and the area of plate transverse section, or $\mathrm{E} \times \mathrm{A}$ ). Evidently, changes in plate width can be regarded as a type of change in stiffness. Different studies have indicated that debonding displacement will be greater with reducing the plate stiffness $[15,22]$. However, the load-displacement curve will also have a milder slope as a result of reduced plate stiffness. Thus, unlike in the case of debonding displacement that can be straightforwardly understood, it is not possible to make any strict judgment on the decrease or increase of the ultimate load; this is because the two parameters of increasing displacement and reducing slope of load-displacement curve have opposite effects on the ultimate load.

Tables 10 and 11 present the effects of changes in plate width on the overall behavior of Rahimi and Swiss Federal Labs' specimens. Figures 19 and 20 illustrate the effects of changes in plate width on the loaddisplacement curve for the aforementioned specimens.

It is clear from Figures 19 and 20 that increased plate width leads to increased slope of load-

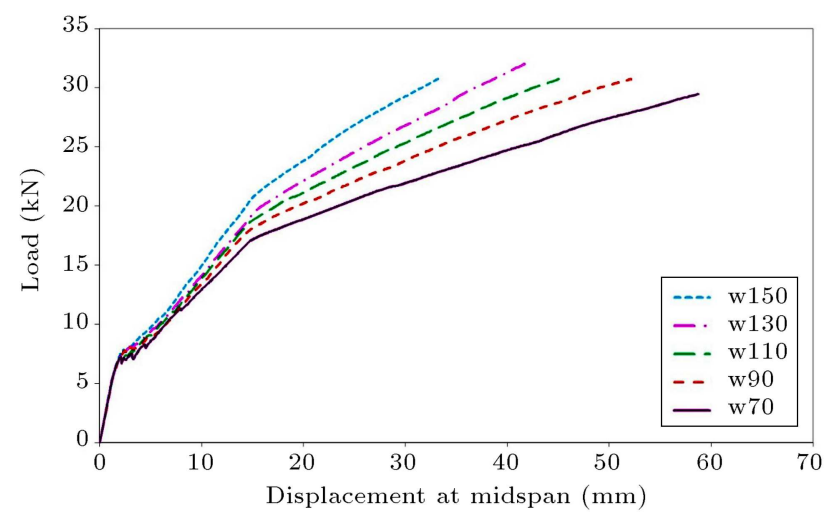

Figure 19. Effect of plate width variation on load-displacement curve in Rahimi's specimen.

Table 10. Effects of plate width variation on behavior for Rahimi's specimen.

\begin{tabular}{|c|c|c|c|c|c|}
\hline \multirow[t]{2}{*}{$\begin{array}{c}\text { Max plate } \\
\text { stress (MPa) }\end{array}$} & \multicolumn{2}{|c|}{$\begin{array}{l}\text { Yielding point of } \\
\text { tensile steel }\end{array}$} & \multicolumn{2}{|l|}{ Failure } & \multirow[t]{2}{*}{$\begin{array}{c}\text { Plate } \\
\text { width }(\mathrm{mm})\end{array}$} \\
\hline & $\begin{array}{l}\text { Displacement } \\
(\mathrm{mm})\end{array}$ & $\begin{array}{l}\text { Load } \\
(\mathrm{kN})\end{array}$ & $\begin{array}{l}\text { Displacement } \\
(\mathrm{mm})\end{array}$ & $\begin{array}{l}\text { Load } \\
(\mathrm{kN})\end{array}$ & \\
\hline 605.1 & 14.34 & 16.70 & 54.27 & 30.48 & 70 \\
\hline 545.1 & 14.28 & 17.70 & 52.10 & 30.73 & 90 \\
\hline 451.8 & 14.27 & 18.28 & 45.02 & 30.76 & 110 \\
\hline 417.5 & 14.81 & 19.13 & 41.67 & 32.03 & 130 \\
\hline 340.5 & 14.48 & 20.19 & 33.17 & 30.77 & 150 \\
\hline
\end{tabular}


Table 11. Effects of plate width variation on behavior for Swiss Federal's specimen.

\begin{tabular}{ccccccc}
\hline $\begin{array}{c}\text { Max plate } \\
\text { stress (MPa) }\end{array}$ & \multicolumn{2}{c}{ Yielding point of tensile steel } & & Failure & \multicolumn{2}{c}{$\begin{array}{c}\text { Plate width } \\
(\mathbf{m m})\end{array}$} \\
\cline { 2 - 3 } \cline { 5 - 6 } & $\begin{array}{c}\text { Displacement } \\
(\mathbf{m m})\end{array}$ & $\begin{array}{c}\text { Load } \\
\mathbf{( k N )}\end{array}$ & & $\begin{array}{c}\text { Displacement } \\
(\mathbf{m m})\end{array}$ & $\begin{array}{c}\text { Load } \\
\mathbf{( k N )}\end{array}$ & \\
\hline 1144 & 8.27 & 18.13 & & 24.38 & 28.65 & 50 \\
1027 & 9.50 & 21.25 & & 23.35 & 34.28 & 85 \\
892 & 9.64 & 22.92 & & 21.18 & 35.79 & 100 \\
736 & 10.03 & 26.55 & & 18.81 & 39.12 & 140 \\
562 & 9.72 & 27.77 & & 17.59 & 40.20 & 160 \\
\hline
\end{tabular}

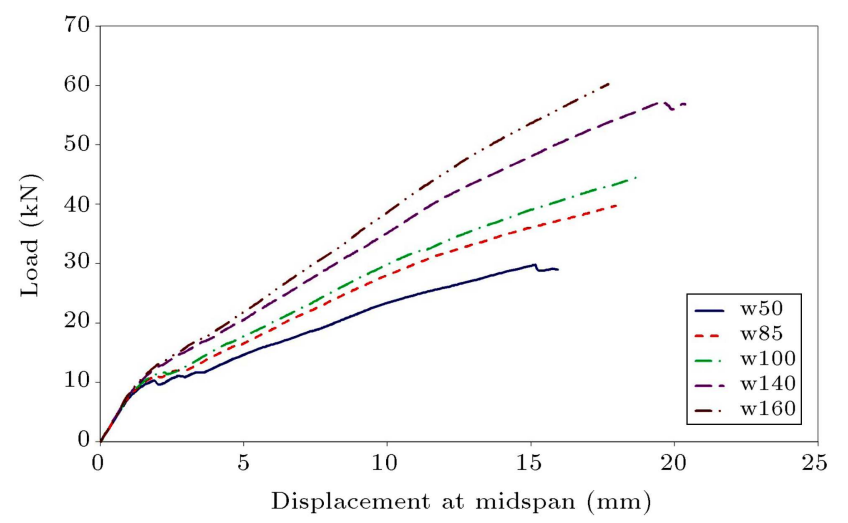

Figure 20. Effect of plate width variation on load-displacement curve in Federal's specimen.

displacement curve but to reduced debonding displacement. However, as already mentioned, no clear judgment can be made about the increase or decrease in the ultimate load. Examination of Tables 10 and 11 reveals that the increased plate width has no considerable effect on Rahimi's specimen. Thus, it seems that both factors of increased stiffness and reduced failure displacement have had equal effects on this specimen. This is while in the Swiss Federal labs' specimen, increased plate width has led to increased failure load but only with a slight rate. Thus, the effect of increased stiffness seems to have been greater than that of reduced displacement in this specimen.

\section{Conclusions}

1. In order to simulate the mid-span debonding of FRP plates in strengthened RC beams, both exerted interfacial stresses and the behavior of the interfacial layer against these stresses must be realistically considered and modeled;

2. To assure that the values and directions of the exerted stresses on the interfacial layer are correctly considered, the proper occurrence of both bending and bending-shear crack's openings in FE analysis is necessary. For this purpose, the size of concrete elements must be smaller than three times the average size of the largest aggregates;

3. The Lu et al. model of interlayer shear stress-slip has adequate accuracy which could be used to reach correct results in FE simulation;

4. In order to induce $\mathrm{Lu}$ et al. relation in FE analysis, cohesive elements available in the Abaqus software could be used. The behavior of these elements may be determined on the basis of two different sets of parameters: those related to pre-debonding failure (linear behavior) and those related to debonding initiation and completion. These parameters must be set according to $\mathrm{Lu}$ et al. relation in order to ensure their proper behavior;

5. Increased plate length has no considerable effect on the trend of load-displacement curve, but it increases the load and the displacement of debonding failure. Increased plate length beyond a certain limit will have a reduced effect on the ultimate load and displacement. In other words, there is an optimum length beyond which no effect may be observed on the behavior of the specimen;

6. Increasing plate width will increase the slope of the load-displacement curve, but it decreases the failure displacement. Increased slope of the loaddisplacement will lead to the increased ultimate load but the decreased failure displacement. That is why no clear judgment can be made about the effect of increased plate width on the failure load.

\section{Nomenclature}

$b_{c}(\mathrm{~mm}) \quad$ Concrete beam width

$b_{p}(\mathrm{~mm}) \quad$ Reinforcing plate width

$f_{t}(\mathrm{MPa}) \quad$ Concrete cracking stress

$G_{f}(\mathrm{~N} / \mathrm{mm})$ Failure energy per area

$G_{f}^{c}(\mathrm{MPa}) \quad$ Area under concrete stress-strain curve

$k_{n n}\left(\mathrm{~N} / \mathrm{mm}^{3}\right)$ Slope of bond-slip function before debonding in normal direction 
$k_{t t}\left(\mathrm{~N} / \mathrm{mm}^{3}\right)$ Slope of bond-slip function before debonding in $t$ direction

$k_{s s}\left(\mathrm{~N} / \mathrm{mm}^{3}\right)$ Slope of bond-slip function before debonding in $s$ direction

$s(\mathrm{~mm}) \quad$ Slip between beam and reinforcing plate

$s_{f}(\mathrm{~mm}) \quad$ Debonding slip of reinforcing plate

$s_{0}(\mathrm{~mm}) \quad$ Slip corresponding maximum shear stress

$t_{n}(\mathrm{MPa}) \quad$ Normal stress in cohesive element

$t_{s}(\mathrm{MPa}) \quad$ Shear stress in cohesive element in $s$ direction

$t_{t}(\mathrm{MPa}) \quad$ Shear stress in cohesive element in $t$ direction

$\beta_{w} \quad$ Shape factor of reinforcing plate

$\tau(\mathrm{MPa}) \quad$ Shear stress in plate and beam interface layer

$\tau_{\max }(\mathrm{MPa})$ Maximum shear stress in plate and beam interface layer

$\delta_{n}(\mathrm{~mm}) \quad$ Relative displacement between two sides of cohesive element in normal direction

$\delta_{s}(\mathrm{~mm}) \quad$ Relative displacement between two sides of cohesive element in $s$ direction

$\delta_{t}(\mathrm{~mm}) \quad$ Relative displacement between two sides of cohesive element in $t$ direction

\section{References}

1. Teng, J.G., Chen, J.F., Smith, S.T. and Lam, L., FRP Strengthened RC Structures, John Wiley \& Sons Ltd., England (2002).

2. Coronado, C. "Characterization, modeling and size effect of concrete-epoxy interfaces", Department of Civil and Environmental Engineering, Pennsylvania State University, PhD Thesis (2006).

3. Greco, F., Lonetti, P. and Blasi, P.N. "An analytical investigation of debonding problems in beams strengthened using composite plates", Engineering Fracture Mechanics, 74(3), pp. 346-372 (2007).

4. Esna Ashari, S. and Mohammadi, S. "Fracture analysis of FRP-reinforced beams by orthotropic XFEM", Journal of Composite Materials, 46, pp. 1367-1389 (2012).

5. Bruno, D., Greco, F. and Lonetti, P. "A fractureALE formulation to predict dynamic debonding in FRP strengthened concrete beams", Composites Part B: Engineering, 46, pp. 46-60 (2013).

6. Täljsten, B. "Strengthening of beams by plate bonding", Journal of Materials in Civil Engineering, 9(4), pp. 206-212 (1997).

7. Wu, Z. and Hemdan, S. "Debonding in FRPstrengthened flexural members with different shearspan ratios", 7th Int. Symposium on Fiber Reinforced
Composite Reinforcement for Concrete Structures, 1, pp. 411-426, Michigan, USA (2005).

8. Wang, J.L. "Debonding of FRP-plated reinforced concrete beam, a bond-slip analysis. I. Theoretical formulation", International Journal of Solids and Structures, 43(21), pp. 6649-6664 (2006).

9. Lu, X.Z., Teng, J.G., Ye, L.P., and Jiang J.J. "Intermediate crack debonding in FRP-strengthened RC beams: FE analysis and strength model", $A S C E$ Journal oF Composites for Construction, 11(2), pp. 161-174 (2007).

10. De Lorenzis, L. and Zavarise, G. "Cohesive zone modeling of interfacial stresses in plated beams", International Journal of Solids and Structures, 46(24), pp. 4181-4191 (2009).

11. Rabinovitch, O. "An extended high order cohesive interface approach to the debonding analysis of FRP strengthened beams", International Journal of Mechanical Sciences, 81, pp. 1-16 (2014).

12. Lu, X.Z., Teng, J.G., Ye, L.P. and Jiang, J.J. "Bondslip models for FRP sheets / plates bonded to concrete", Engineering Structures, 27(6), pp. 920-937 (2005).

13. Abdelbaky, H. "Nonlinear micromechanics-based finite element analysis of the interfacial behavior of FRPstrengthened reinforced concrete beams", Department of Civil Engineering, Sherbrooke University, Canada, PhD Thesis (2008).

14. Hu, H.T., Lin, F.M. and Jan, Y.Y. "Nonlinear finite element analysis of reinforced concrete beams strengthened by fiber reinforced plastics", Composites for Construction, 63, pp. 271-281 (2001).

15. Rahimi, H. and Hutchinson, A. "Concrete beams strengthened with externally bonded FRP plates", Composites for Construction, 5(1), pp. 44-56 (2001).

16. Aram, M.R., Czaderski, C. and Motavalli, M. "Debonding failure modes of flexural FRP strengthened RC beams", Composites Part B, 39, pp. 826-841 (2008).

17. Lu, F. and Ayoub, A. "Evaluation of debonding failure of reinforced concrete girders strengthened in flexure with FRP laminates using finite element modeling", Construction and Building Materials, 25(4), pp. 19631979 (2011).

18. Saxena, P. "Interfacial bond behavior between FRP and concrete substrate", The Department of Civil and Environmental Engineering, University of Alabama, Master Thesis, Alabama (2006).

19. Hosseini, S.J. "Modeling of FRP-concrete interface debonding in strengthened reinforced concrete beams with some case studies", The Department of Civil Engineering, Isfahan University of Technology, Master Thesis, Isfahan (2009).

20. ABAQUS Inc. "ABAQUS/theory user manual; Version 6.7", Dassault Systèmes, Providence, RI, USA (2007). 
21. Wu, Z.S. and Kurokawa, T. "Strengthening effects and effective anchorage method for flexural members with externally bonded CFRP plates", JSCE Journal of Material, Concrete Structures and Pavements, 56, pp. 1-13 (2002).

22. Yao, J. "Debonding failures in RC beams and slabs strengthened with FRP plates", Department of Civil and Structural Engineering, Hong Kong Polytechnic University, PhD Thesis, Hong Kong (2004).

23. Mostofinejad, D., Reinforced Concrete Structures, 1, 34th edition, Arkan Danesh Publisher, Isfahan, Iran (2014).

24. ACI Committee 318, Building Code Requirements for Structural Concrete (ACI 318-14) and Commentary, American Concrete Institute, Detroit, Mich, USA (2014).

25. Chung, W.S. "A cracked concrete material model for the nonlinear finite element analysis of slab-on-girder bridges", Purdue University, PhD Thesis (2003).

26. ACI Committee 224, Cracking of Concrete Members in Direct Tension, American Concrete Institute, Detroit, Mich, USA (1997).

27. ACI Committee 440, Guide for the Design and Construction of Externally Bonded FRP Systems for Strengthening Concrete Structures, ACI 440.2R-08, Farmington Hills, MI, USA (2008).

28. Maruyama, K. "Recommendations for upgrading of concrete structures with use of continuous fiber sheets", Research Committee on Upgrading of Con- crete Structures with use of Continuous Fiber Sheets, Japan Society of Civil Engineers (JSCE) (2001).

29. WhaBai, J. "Seismic retrofit for reinforced concrete building structures", Consequence based engineering (CEB) Institute Final Report, Texas University (2003).

\section{Biographies}

Davood Mostofinejad received the BS degree in Civil Engineering from Tehran University, Iran, 1985, and $\mathrm{MSc}$ and $\mathrm{PhD}$ degrees from the Isfahan University of Technology and Carleton University, 1987 and 1997, respectively. He is currently a Distinguished Professor of Concrete Engineering at Department of Civil Engineering in Isfahan University of Technology, Isfahan, Iran. His research interests lie in the application of Fiber Reinforced Polymer (FRP) in concrete and masonry structures. He has published over 190 research articles and 13 books.

Saied Jalil Hosseini received the BS and MSc degrees in Civil Engineering from Isfahan University of Technology, 2005 and 2009, respectively. He is currently a $\mathrm{PhD}$ candidate in Structural Engineering at Department of Civil Engineering in the same University. His research interests lie in the Application of Fiber Reinforced Polymer (FRP) in concrete structures. He has published 2 journal articles. 